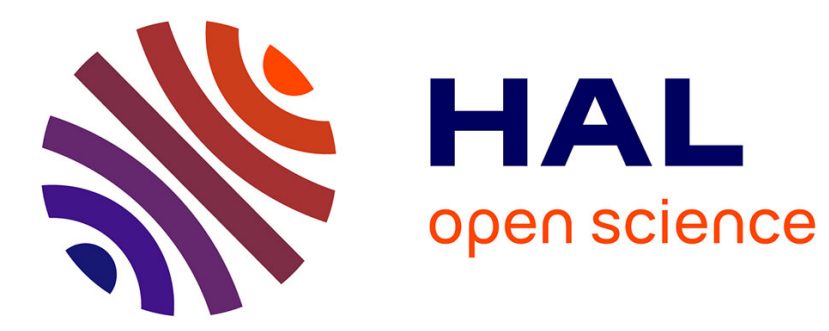

\title{
Experimental measurement of flow distribution in a parallel mini-channel fluidic network using PIV technique
}

\author{
Guillaume Boutin, Min Wei, Yilin Fan, Lingai Luo
}

\section{To cite this version:}

Guillaume Boutin, Min Wei, Yilin Fan, Lingai Luo. Experimental measurement of flow distribution in a parallel mini-channel fluidic network using PIV technique. Asia-Pacific Journal of Chemical Engineering, 2016, 11 (4), pp.630-641. 10.1002/apj.2013 . hal-03155819

\section{HAL Id: hal-03155819 https://hal.science/hal-03155819}

Submitted on 2 Mar 2021

HAL is a multi-disciplinary open access archive for the deposit and dissemination of scientific research documents, whether they are published or not. The documents may come from teaching and research institutions in France or abroad, or from public or private research centers.
L'archive ouverte pluridisciplinaire HAL, est destinée au dépôt et à la diffusion de documents scientifiques de niveau recherche, publiés ou non, émanant des établissements d'enseignement et de recherche français ou étrangers, des laboratoires publics ou privés. 


\section{Experimental Measurement of Flow Distribution in a Parallel Mini-channel Fluidic Network using PIV Technique}

\author{
Guillaume BOUTIN ${ }^{\mathrm{a}}$, Min WEI ${ }^{\mathrm{a}}$, Yilin FAN ${ }^{\mathrm{a}}$, Lingai LUO $^{\mathrm{a}}{ }^{*}$ \\ ${ }^{a}$ Laboratoire de Thermocinétique de Nantes, UMR CNRS 6607, Polytech' Nantes - \\ Université de Nantes, La Chantrerie, Rue Christian Pauc, BP 50609, 44306 Nantes Cedex 03, \\ France
}

\begin{abstract}
Fluid flow distribution among parallel channels usually plays an important role on the global performance improvement of tubular process equipment, but remains difficult to be properly measured by experimental methods. This paper presents a systematic study on the measurement of flow distribution in a multi-channels fluidic network using PIV technique. For the precise measurement of flow-rate in each individual channel, standard 2D-2C PIV technique is used to obtain velocity vectors on multiple sampling planes parallel to the flow direction, so as to reconstruct accurate velocity profiles on the cross-sectional surface. Such procedure is repeated for every micro- (mini-) channel to obtain the actual flow distribution properties in the fluidic network.
\end{abstract}

Pre-test results on a double-channels device indicate that the maximum possible deviation of PIV measurements is $13.1 \%$ with respect to those of a flange flowmeter, implying that the PIV technique is relatively accurate and reliable. PIV results on the flow distribution in a 15channels fluidic network are then compared with CFD simulation results under the same working conditions. A quite good agreement could be observed. Moreover, the locations and sizes of vortices in the distributor have a significant influence on the flow distribution.

\section{Keywords:}

Flow distribution; Fluidic network; PIV; Parallel channels; Streamline profile; CFD

${ }^{*}$ Corresponding author. Tel.: +33 240683167; Fax: +33 240683141. E-mail address: lingai.luo@univ-nantes.fr 


\section{Introduction}

2

3

4

5

6

7

8

9

10

11

12

13

14

Multi-channel micro- or mini-fluidic equipment usually consists of one inlet distributor, a number of parallel micro- or mini-channels and one outlet collector. They are widely used in process engineering and energy conversion systems, such as heat exchangers, chemical reactors, catalytic monoliths or fuel cells ${ }^{[1]}$. The fluid flow distribution among the parallel channels may play an important role on the achievement or improvement of their global performance ${ }^{[2-7]}$. Therefore, the precise measurement of mass (volume) flow-rate in each individual channel and then the flow distribution properties among parallel channels are essential steps for the diagnostic and improvement of flow distribution quality.

With the significant advances on computing algorithms and facilities, Computational Fluid Dynamics (CFD) approaches are intensively used in the last decades for the prediction of flow distribution, for preliminary designs and for the optimization of manifold geometries to achieve certain objectives ${ }^{[7-10]}$. Nevertheless, the current CFD techniques still have some difficulties for correctly describing turbulent flows, vortex or curvature flows and multi-phase flows. Furthermore, the numerical errors and uncertainties linked to the mesh quality and selected models require that CFD results must be validated by experimental measurements.

Recently, the development of reliable experimental approaches for the measurement of fluid flow distribution among parallel channels receives much attention. Current available methods in the literature may be classified into two main categories: intrusive and non-intrusive methods. One straightforward intrusive method is the weighting method ${ }^{[11-13]}$, by weighting out the mass of fluid collected from each individual channel/tube during a typical sampling time when the flow-rate is stabilized. This method is relatively simple to operate by using a digital balance and a stop watch, but unfortunately cannot be applied to an enclosed parallel channels fluidic network due to the presence of the fluid collector.

Other intrusive methods are usually based on the establishment of relationships between the flow-rate (or flow velocity) and another physical quantity which can be measured easily. For example, the mean fluid velocity in a channel may be obtained by measuring the difference between the static and dynamic pressures using a Pitot tube pointing directly into the fluid flow and then by solving the Bernoulli's equation. Hot Wire Anemometry (HWA) is based on the measurement of convective heat transfer coefficient between the heated wire and the surrounding flow velocity. Due to the scalar quantity measurement, however, HWA is incapable of determining the direction of fluid flow. Other intrusive flowmeters include orifice plate meter, Venturi meter, variable area meter, positive displacement flowmeter, turbine and related flowmeter, vortex-shedding flowmeter, etc. More details on these instruments and their basic principles may be found in the books of Baker ${ }^{[14]}$ and LaNasa and $\mathrm{Upp}^{[15]}$.

Although the intrusive methods are relatively easy for implementation and operation, they may not be suitable for flow distribution measurement in micro- or mini-channel fluidic networks. Firstly, most of the flowmeters without probes may occupy a large volume compared to micro- or mini-channel. For example the minimum required piping is about 10 $\mathrm{mm}$ for Venturi meter, and about $25 \mathrm{~mm}$ for liquid turbine meter ${ }^{[15]}$. Some micro sensors may be commercially available but are either immature or very expensive ${ }^{[16]}$. Secondly, the variation of measurement locations required for multiple channels devices is relatively difficult to be realized. Thirdly, the intrusive methods will inevitably change the flow paths of the fluidic network (for example the removal of the outlet collector for the weighting method), or disturb the established streamline profiles due to additional boundary conditions of the 
measurement equipment (for example the insertion of different probes). Hence, intrusive methods are difficult to be applied for precise measurement of flow distribution in micro- or mini-channel fluidic networks.

To overcome aforementioned drawbacks, non-intrusive techniques become well-developed which usually involve the flow visualization. Some researchers ${ }^{[17-19]}$ tried to obtain more detailed fluid flow characteristics through the estimation of Residence Time Distribution (RTD) inside the device. Concentration meters or spectrometers are usually used to measure the concentration variation of indicator at the outlet. In this case, the inevitable diffusion between the indicator and the fluid flow and the theoretical mixing models used may have great influences on the precision of the measurement results.

Another significant advance in optical-based non-intrusive flow measurement is the LaserDoppler Velocimetry (LDV), which consists of laser transmitting and receiving optics and the seeding particles mixed in the measured fluid flow. It is based on the Doppler effect which is the linear change of laser light frequency proportional to the velocity of seeding particles. LDV technique has various features, i.e., linear output signal, no calibrations required, high frequency response and direct velocity measurement. When opaque fluid flow (e.g. liquid slurries) is involved, Doppler Ultrasonic Velocimetry (DUV) using the ultrasound instead of laser is a suitable alternative. Both LDV and DUV can offer good spatial and temporal resolutions, but are limited by single point measurement. Multipoint measurement for parallel channels is theoretically feasible with a combination of many measured points, but may practically be prohibitive due to the heavy workload.

Recently, Particle Image Velocimetry (PIV) technique has undergone a rapid development which benefits from the advances in laser and camera technologies. Different from LDV, PIV takes the images of seeding particles suspended in the fluid flow while the local fluid velocity vectors are measured by the displacement of various particles within a short time interval. More precisely, the laser is introduced to illuminate the seeding particles in a plane twice in a known time interval while the light scattered by the particles is recorded by a Charge Coupled Device (CCD) camera equipped with a lens on a sequence of two frames. The images are then digitized and transferred directly to the memory of a computer. After that, an individual image is divided into a number of interrogation windows, the mean displacement of all particles in each interrogation window being calculated with statistical methods (such as the crosscorrelation) through post-processing. Finally, the whole flow field in the plane can be established based on the velocity vectors of all interrogation windows. More details on the PIV technique may be found in relevant review articles ${ }^{[20-25]}$. A general comparison between various frequently-used techniques for micro- or mini-fluidic flow measurements are presented in Table 1. It can be noted that PIV is a non-intrusive, whole field method with possible high resolution and precision.

PIV technique used in microfluidics (or called $\mu$ PIV) was firstly introduced by Santiago et al. ${ }^{[26]}$. In their study, the movement of particles tagged with fluorescent dye was recorded under a continuous Hg-arc lamp by CCD camera. After the introduction of laser illumination by Meinhart et al. ${ }^{[27]}$, abundant studies in the literature have been devoted to the improvement of PIV technique for flow field measurement. However, most of these studies were focused on single channel ${ }^{[27-33]}$, or at best on two parallel channels ${ }^{[34]}$. A noticeable exception is the study of Wen et al. ${ }^{[35]}$ which measured the flow-rate distribution among multiple outlets of an individual gas distributor. The distributor had a conventional dimension of $905 \mathrm{~mm}$ in length and $154 \mathrm{~mm}$ in radius, with a middle inlet pipe of $176 \mathrm{~mm}$ in length and $200 \mathrm{~mm}$ in diameter. 41 parallel tubes with the width of $9.5 \mathrm{~mm}$ served as the outlets of the distributor. Although 
the gas distribution properties among parallel outlets were measured by PIV technique, only one plane parallel to the flow direction was selected as the sampling plane for each outlet. Actually, the velocity vectors on a single plane parallel to the flow direction cannot correctly reflect the velocity profiles on the channel's cross-sectional surface (Fig. 4 as an example). Consequently, noticeable measurement errors and uncertainties on the flow-rate seem inevitable. Moreover, the effect of boundary layers may greatly affect the flow distribution, especially in micro- or mini-channels. To the best of our knowledge, systematic and precise measurement of flow distribution among multiple micro- (mini-) channels using PIV technique is still lacking.

Table 1: Comparison between various frequently-used microfluidic measurements

As a result, the present study aims at realizing PIV measurement of the flow-rates in parallel channels and studying the fluid flow distribution in a multiple channels fluidic network. To do this, two steps are programmed. Firstly for the precise measurement of flow-rate in a single channel, standard PIV technique will be used to obtain the 2D-2C (2 dimensions, 2 components) velocity vectors on multiple planes parallel to the flow direction, so as to reconstruct accurate velocity profiles on the cross-sectional surface taking the potential effects of boundary layers into account. Secondly, such procedure will be repeated for every micro(mini-) channel in the fluidic network so as to obtain the actual flow distribution properties among parallel channels.

In the rest of this paper, we shall first introduce the experimental set-up and the PIV instruments used in this study. The measurement parameters, the experimental procedure and the uncertainty will be discussed using a double-channels device as an example. Then, a minifluidic network having 15 parallel channels will be tested under different total inlet flow-rate conditions. The flow-rate distribution among parallel channels obtained by PIV technique will be compared with CFD simulation results under the same operational conditions. Finally, remarks and main conclusions will be summarized.

\section{Experimental set-up and PIV instruments}

\subsection{Test-rig}

Figure 1 shows the schematic diagram of the experimental set-up built in the laboratory LTN in Nantes, France. It consists of fluid circuit and PIV measurement facility. The working fluid used in this study was pure water. In the fluid circuit, water was pumped from a $300 \mathrm{~L}$ water tank, then passed through the test section (mini-channels device), and finally returned back to the water tank to form a closed loop. Due to the wide range of tested flow-rate conditions, two pumps were installed in the test-rig: a gear pump (MICROPUMP, O/CGC-M35.PVSF) with a measurement range of $1-5 \mathrm{~L} \cdot \mathrm{min}^{-1}$ and a precise pump (VWR, REGLO-Z) with a measurement range of $32-3200 \mathrm{~mL} \cdot \mathrm{min}^{-1}$. A tee joint was installed in the fluid circuit for the alternation of different pumps. The output flow-rate can be measured by a flange flowmeter (KOBOLD, DPL-1P15GL443, 0.2-6 L $\cdot \mathrm{min}^{-1}$ ) with $\pm 2.5 \%$ instrumental error of the full scale (e.g., $0.15 \mathrm{~L} \cdot \mathrm{min}^{-1}$ ) when the gear pump was used. For the precise pump, the flow-rate can be obtained by its own readings. Fresh water was introduced to clean the mini-channel device after each series of tests and a filter was used to avoid the discharge of sewage. 
Figure 1: Schematic diagram of experimental setup

\subsection{PIV instruments}

Standard 2D-2C PIV facility was used in our study. It consists of illumination unit, image record unit, synchronous controlling unit and data processing unit. The light source used was Nd-Yag laser (Litron Incorporation, DualPower 65-15 DANTEC laser) with a second harmonic generator which can produce a Q-switched output. The pulse energy was $65 \mathrm{~mJ}$ with the duration of $4 \mathrm{~ns}$. The light wavelength was $532 \mathrm{~nm}$ and the diameter of light beam was $6.5 \mathrm{~mm}$. The pulse frequency equaled to $5 \mathrm{~Hz}$, indicating that the fluid flow was recorded five times per second. The optical head was also a part of illumination unit which was installed at the end of laser guide. Consisting of spherical and cylindrical lenses, the pulse laser beam was converted into a pulse light sheet. The position (in the range of $200 \mathrm{~mm}$ to $1000 \mathrm{~mm}, 600 \mathrm{~mm}$ was used in the present study) and the thickness of the light sheet can be adjusted by a commercial optical unit (DANTEC, $80 \times 63$ ).

The light scattered from the particles was collected by a CCD camera (DANTEC, FlowSense) with $2048 \times 2048$ pixels. The minimum time interval between two frames was $1 \mu \mathrm{s}$. An additional macro LAVISION lens was used to yield a magnification of about $260 \mathrm{pixel} \cdot \mathrm{mm}^{-1}$ for double-channels device and about $230 \mathrm{pixel} \cdot \mathrm{mm}^{-1}$ for 15 -channels device. Therefore, the view field was $7.87 \mathrm{~mm} \times 7.87 \mathrm{~mm}$ and $8.73 \mathrm{~mm} \times 8.73 \mathrm{~mm}$, respectively. Note that the frame must be recorded when the laser sheet outputs, so a synchronizer (DANTEC, 80N77) was used to guarantee that the laser and the CCD camera work synchronously. A commercial software FlowManager (v3.41) was used to control the PIV system and to process the data by 2-frame cross-correlation and Fast Fourier Transforms (FFTs). After that, the velocity vector profiles could be obtained. In the current study, the size of the PIV interrogation window was fixed at $16 \times 16$ pixels with an overlap of $50 \%$ after several attempts considering a compromise between the measurement accuracy and the computational time. The spatial resolution of PIV is determined by 2.8 times of the size of interrogation window ${ }^{[21]}$. Therefore, the physical spatial resolution was $0.17 \mathrm{~mm}$ for double-channels device and $0.19 \mathrm{~mm}$ for 15 -channels device, respectively.

A workbench which permits the subtle movements of the test-section was specially designed and built. The camera may be moved in $x$ direction whereas the platform to fix the test-section is moveable in $y$ and $z$ directions, as shown in Fig. 2. The movements in $x$ and $y$ directions were realized using steel orbits while the movement of the platform along $z$ direction was realized using a precise lift and a digital gauge with an accuracy of $0.01 \mathrm{~mm}$. Due to the different scattered light optical paths, the focus of the lens must be adjusted for each vertical plane, leading to different magnification ratios which must be taken into account in the postprocessing. It should be noted that the platform can also be rotated around $z$-axis to ensure a fine overlap between the walls of channels and the boundaries of the PIV interrogation window.

Figure 2: Schematic view of the experimental workbench for subtle movements of the test-section

Polyamid Seeding Particles (PSP-5) supplied by DANTEC Company were used as seeding in our study with good chemical stability and environmental friendliness. The particle density is $1030 \mathrm{~kg} \cdot \mathrm{m}^{-3}$ and the diameter of particles ranges from $1 \mu \mathrm{m}$ to $10 \mu \mathrm{m}$ with the average of 5 $\mu \mathrm{m}$. The Stokes number of PSP-5 is less than 1, indicating that the particles follow the flow 
streamlines well. A stirrer was employed in the water tank to ensure a homogeneous spatial distribution of the seeding particles in the working fluid flow. The proportion of seeding was adjusted during the experiments to ensure at least 10 particles existing in a single interrogation window ${ }^{[36]}$.

\section{3. Measuring procedure and pre-test results}

6

7

8

9

40

We will introduce in detail in this section the measuring procedure of flow-rate distribution by 2D-2C PIV technique. To verify the effectiveness of our method, a double-channels device was fabricated and tested as a benchmark study. The results obtained by PIV measurements were compared with the values of flowmeter to determine the range of deviation.

\subsection{Double-channels device for pre-test}

A double-channels device was fabricated in house using Polymethyl Methacrylate (PMMA) material, as shown in Fig. 3, for the purpose of confirming the feasibility of the 2D-2C PIV technique for parallel channels under multiple refractions. Each channel has a square crosssection of $5 \mathrm{~mm} \times 5 \mathrm{~mm}$, the hydraulic diameter thus being $5 \mathrm{~mm}$. The total channel length is $320 \mathrm{~mm}$ (the transparent part being $100 \mathrm{~mm}$ ), longer than 20 times of its hydraulic diameter to ensure the fully-developed flow ${ }^{[37]}$. The distance between the axes of two channels is $15 \mathrm{~mm}$. The channel closer to the laser source is named as $\mathrm{CH} 1$ while the other one is named as $\mathrm{CH} 2$. A static pressure probe and a valve were installed at the inlet of each channel to adjust the balanced flow-rates needed in the following test.

Figure 3: The geometry and dimensions of double-channels device: (a) schematic view (unit: mm); (b) photo view

\subsection{Measuring procedure and post-processing}

Recall that the 2D-2C PIV technique yields the flow velocity field on a certain plane. We define the middle plane of channels parallel to the flow direction as the base plane $(z=0)$ so that the cross-section of channels ranges from $z=-2.5 \mathrm{~mm}$ to $z=+2.5 \mathrm{~mm}$. In order to construct accurate fluid flow field, the cross-section of channels was divided into 21 planes along $z$ axis, with a stepping distance of $0.25 \mathrm{~mm}$ to be measured. It should be noted that the laser source was fixed so that the device should be moved vertically along $z$ direction for different measuring planes, using the adjustable workbench described in Section 2.2.

For each measuring plane, a large number of frames (200 or 375 pairs in this study) should be captured and averaged to eliminate the random errors. Likewise, different planes were measured successively to obtain the fluid flow velocity vectors in $y-z$ plane. Note that for each plane, the acquisition parameters (e.g., the focus of the lens, the time interval between two laser pulses, and the laser energy) should be adjusted according to different vertical positions, implying different magnifications of lens. In the post-processing, different relationships between the actual length (the width of channel in this study) and the corresponding numbers of pixels should be used by introducing a magnification ratio $G$ defined as follows:

$G=\frac{N}{l}$ 
where $l$ is the width of the channel and $N$ is the corresponding pixel numbers in the captured 2 image. Due to non-identical values of $G$ for different measured planes, the actual velocity $U$ 3 should be recalculated as follows:

$4 \quad U=\frac{U^{\prime}}{G \Delta t}$

5

6

$25 \quad \operatorname{Re}=\frac{d_{h} \bar{U} \rho}{\mu}$ as:

where $U^{\prime}$ is the flow velocity obtained by PIV post-processing under the unit of pixels/frame and $\Delta t$ is the time interval between two frames. A MATLAB programme was built to handle the calculation process automatically.

Once the unit conversions for all measuring planes were finished, a fixed physical position (for example the middle of the image) for all measuring planes was chosen as the transverse surface and the fluid flow velocity profiles at $y-z$ surface could be obtained, as an example shown in Fig. 4. The boundary layers near the side walls could be clearly observed while those near the top and bottom walls are less obvious. That is due to the fact that the spatial resolution is less accurate in vertical direction ( $z$ direction) than in horizontal direction ( $y$ direction). Indeed, the horizontal spatial resolution is determined by the size of interrogation window $(0.17 \mathrm{~mm}$ in this study) while the vertical spatial resolution is limited by the stepping distance $(0.25 \mathrm{~mm})$ combined with the laser sheet thickness $(0.11 \mathrm{~mm})$. For more accurate description of the top and bottom boundary layers, a smaller stepping distance could be used which means more sampling $x-y$ planes.

Based on the fluid flow velocity profiles at $y-z$ surface (cross-section), the mass flow-rate $m$ passing through the channel can be easily obtained as follows:

$m=\rho Q=\rho \int_{S} U d S$

where $Q$ is the volume flow-rate, $S$ is the area of the cross-section of the channel and $\rho$ is the density of water used in our study $\left(998.2 \mathrm{~kg} \cdot \mathrm{m}^{-3}\right)$. The channel Reynolds number is calculated

where $\bar{U}$ is the mean fluid velocity in a channel, $\mu$ the dynamic viscosity of water and $d_{h}$ the hydraulic diameter of the channel calculated as:

$$
d_{h}=\frac{4 S}{A}
$$

where $A$ is the perimeter of the channel's cross-section.

Figure 4: Example of fluid flow velocity profile at the cross-sectional surface of a channel

It should be noted that due to the limitation of the test view of PIV, at most two channels can be measured together each time. For the 15-channels device with $2 \mathrm{~mm}$ in depth, eight successive measurements (thus 72 planes) should be processed to obtain the fluid flow distribution properties among parallel channels. 


\subsection{Results of pre-test and uncertainty analysis}

2

3

4

5

6

7

8

9

10

In order to analyze the uncertainty of the 2D-2C PIV technique, three cases of pre-test were carried out. In Case 1, the fluid flow just passed through $\mathrm{CH} 1$ as a standard PIV measurement in single channel. In Case 2, the fluid flow was injected through $\mathrm{CH} 2$ while $\mathrm{CH} 1$ was filled with stilled water to simulate a parallel channel configuration, so that the laser sheet had to pass through $\mathrm{CH} 1$ firstly before reaching $\mathrm{CH} 2$. In Case 3, the volume flow-rates in both channels were measured simultaneously, with balanced flow-rates adjusted according to the static pressure probes. The results obtained by PIV $\left(Q_{p}\right)$ were compared with the measurements of the flowmeter $\left(Q_{f}\right)$, as listed in Table 2 . Recall that the flowmeter has a $\pm 2.5 \%$ maximum instrumental uncertainty. Therefore, the minimum and maximum deviations of the PIV measurements are defined as follows:

$\varepsilon_{\min / \max }=\left|\frac{Q_{p}-\left(Q_{f} \pm 0.15\right)}{Q_{f} \pm 0.15}\right|$

Two numbers of instantaneous frames, 200 and 375, were used to test the image independence in Cases 1 and 2. It can be seen from Table 2 that the maximum deviation is less than $0.1 \%$. Therefore, 200 pairs of frames for each plane were enough for the rest of the experiments. It can also be seen that the results obtained by PIV show a good agreement with the values of flowmeter. The maximum possible deviation is $13.1 \%$ (will be indicated as the error bars for PIV results in the following figures), implying that the PIV technique is relatively accurate and reliable for flow-rate measurement.

Table 2: The results of different cases in pre-test

\section{Measurement of flow-rate distribution in a multi-channel fluidic network}

After the pre-test and uncertainty analysis of the 2D-2C PIV technique using the doublechannels device, a 15-channels device with integrated distributor and collector was fabricated and tested to show the effectiveness and the validity of the experimental method. The results obtained by PIV are also compared with CFD simulation results under different total flow-rate conditions.

\subsection{5-channels device}

A mini-channels fluidic network consisting of 15 parallel channels, a distributor and a collector was used for study, as shown in Fig. 5. The overall dimension is $242 \mathrm{~mm}$ in length and $90 \mathrm{~mm}$ in width. For the convenience of fabrication, the entire fluidic network has the identical channel depth $(e=2 \mathrm{~mm})$. The inlet and outlet channels located in diagonal position have the same width of $5 \mathrm{~mm}$, but different lengths $(50 \mathrm{~mm}$ for inlet tube and $100 \mathrm{~mm}$ for outlet tube). The length of the distributing manifold is $13 \mathrm{~mm}$ and the width is $90 \mathrm{~mm}$. Identical dimensions are used for the collecting manifold (length of $13 \mathrm{~mm}$ and width of 90 $\mathrm{mm})$. There are fifteen parallel straight channels with identical width of $2 \mathrm{~mm}$, length of 60 $\mathrm{mm}$ and depth of $2 \mathrm{~mm}$. They are evenly spaced at $4 \mathrm{~mm}$ between the axis of one channel and another. For the convenience of description, they are indexed by $k$ from 1 to $M$ from the inlet side to the outlet side. By this way, the mass flow-rate in $k$ th channel is notated as $m_{k}$. The flow-rate ratio $\sigma$ is introduced for each channel as follows: 
$1 \quad \sigma_{k}=\frac{m_{k}}{\bar{m}}$

2 where $\bar{m}$ is the average mass flow-rate among 15 channels given by:

$3 \quad \bar{m}=\frac{\sum_{k=1}^{M} m_{k}}{M}$

4

5

6

7

8

9

10

11

12

13

14

Figure 5: The geometry and dimensions of 15-channels fluidic network. (a) Cube A; (b) Cube B (unit: mm); (c) Photo view after assembling

The device was also fabricated in the laboratory LTN by carving the network on the surface of a PMMA cube (cube A), as shown in Fig. 5a. Six edge fillets having the same radius of 1 mm may be observed at different corners of the fluidic. Another PMMA cube (cube B) was also carved to form the enclosed fluidic network, as shown in Fig. 5b. To prevent the water leakage, a number of grooves were reserved around the network or between the parallel channels, and filled with rubble strips. Moreover, 29 bolts were used for sealing and the tightness of the test-section was verified before every test to avoid water leakage. The photo view of the 15-channels device after assembling may be found in Fig. 5c.

\subsection{CFD simulation parameters}

3D CFD simulation was also performed to calculate the flow-rate distribution among 15 parallel channels and to compare with the PIV measurements. The geometrical characteristics used in the simulation were exactly the same as the fabricated device, including the edge fillets. The working fluid used was pure water at ambient temperature with density of 998.2 $\mathrm{kg} \cdot \mathrm{m}^{-3}$ and viscosity of $1.003 \times 10^{-3} \mathrm{~kg} \cdot \mathrm{m}^{-1} \cdot \mathrm{s}^{-1}$. The inlet mass flow-rate was set to be constant according to different operation conditions. The operational pressure was fixed at $101325 \mathrm{~Pa}$. Simulations were performed under steady state, incompressible and isothermal condition without heat transfer. The gravity effect at $-z$ direction was also taken into account.

A commercial code FLUENT (version 12.1.4) was used to solve the Navier-Stokes equations. The fluid flow was calculated by the COUPLED method for pressure-velocity coupling, and second-order upwind differential scheme was applied for discretization of momentum and standard method for pressure. Laminar or standard $k-\varepsilon$ model was used to simulate the laminar or turbulent flow, respectively. Constant mass flow-rate at inlet surface was given and the boundary condition of outlet was set as pressure-outlet with zero static pressure. Adiabatic wall condition was applied and no slip occurred at the wall. The solution was considered to be converged when 1) sums of the normalized residuals for control equations were all less than $1 \times 10^{-6}$; and 2) the mass flow-rate at each channel was constant from one iteration to the next (less than $0.5 \%$ variation).

The grid density used in the study was 5 segments per millimeter (1.42 million elements in total) and structured mesh was generated using software ICEM (version 12.1) to build up the geometry model. A grid independence study was performed with a refined mesh (8 segments per millimeter; 5.49 million elements in total). Simulation results with the inlet volume flowrate of $1.8 \mathrm{~L} \cdot \mathrm{min}^{-1}$ indicated a difference of about $3.2 \%$ on the inlet pressure. For the mass flow-rate in each channel, the maximum difference was less than $4.9 \%$. Therefore, the normal mesh was used as a compromise between the calculation time and the precision while the value of $4.9 \%$ was indicated as error bars for the CFD results in the following figures. 


\subsection{Results and discussions}

2

Two different inlet total fluid flow-rates $\left(Q_{i n}\right)$ were tested in this study, i.e. high inlet flow-rate of $1.8 \mathrm{~L} \cdot \mathrm{min}^{-1}$ and low inlet flow-rate of $0.18 \mathrm{~L} \cdot \mathrm{min}^{-1}$, in order to cover both the laminar and the turbulent flow patterns. The corresponding Re number at the inlet channel $\left(\mathrm{Re}_{i n}\right)$ was 8500 and 850 , respectively. The mean $\mathrm{Re}$ number in the parallel channels $\left(\operatorname{Re}_{c h}\right)$ was 1000 for $Q_{i n}=1.8 \mathrm{~L} \cdot \mathrm{min}^{-1}$ and 100 for $Q_{i n}=0.18 \mathrm{~L} \cdot \mathrm{min}^{-1}$. The numerical (CFD) and experimental (PIV) results on fluid flow distribution among the 15 parallel channels are shown in Fig. 6.

8

9

10

11

12

13

14

Figure 6: The flow distribution properties obtained by PIV and CFD under different inlet flow-rate conditions. (a) $Q_{i n}=0.18 \mathrm{~L} \cdot \mathrm{min}^{-1}$, mean $\operatorname{Re}_{c h}=100$; (b) $Q_{i n}=1.8 \mathrm{~L} \cdot \mathrm{min}^{-1}$, mean $\operatorname{Re}_{c h}=1000$

Under low inlet flow-rate condition $\left(Q_{i n}=0.18 \mathrm{~L} \cdot \mathrm{min}^{-1}\right.$; mean $\left.\mathrm{Re}_{c h}=100\right)$, the flow distribution curve appears a V-like shape, as shown in Fig. 6a. The values of flow-rate are relatively high $\left(\sigma_{k}>1.5\right)$ in channels facing to the inlet tube (e.g. channels 1 and 2) and then decrease rapidly to the lowest in channel 4. After that, a slow increase of flow-rate appears till the channel 15 which is the farthest channel from the inlet tube. The flow distribution is obviously nonuniform, with the $\sigma_{k}$ values ranging from 0.55 to 2.72 (PIV results). It can also be observed that the CFD and PIV results are in good agreement, implying that the laminar model is capable of correctly simulating the fluid flow under low flow-rate condition.

CFD and PIV results on flow distribution under high inlet flow-rate condition $\left(Q_{i n}=1.8 \mathrm{~L} \cdot \mathrm{min}^{-}\right.$ ${ }^{1}$; mean $\mathrm{Re}_{c h}=1000$ ) are shown in Fig. 6b. A similar but less uniform distribution curve (Ulike shape) may be observed compared to that under low-rate condition, with $\sigma_{k}$ values ranging from 0.04 to 4.00 (PIV results). It may be observed that the CFD results are in good agreement with the PIV results for the general tendency. However, noticeable discrepancies may also be observed especially for channels 5-9, implying the potential difficulties in simulation caused by turbulence and vortex flows.

In order to better validate the CFD simulations by PIV measurement, a detailed examination on the fluid flow streamlines in the distributor was carried out. Due to the limitation of view field, the inlet distributor section was divided into seven independent parts which were successively recorded by the CCD camera when the fluid flow was stable, each part having 200 instantaneous frames for the PIV post-treatment. These parts were then processed and connected so as to reconstruct the fluid flow streamlines in the whole distributor section, except for a narrow bar area which is not transparent due to fabrication limitation. Results under low and high inlet flow-rate conditions are presented in Fig. 7 and Fig. 8, respectively. Corresponding flow streamlines obtained by CFD simulation under the same working conditions are also included for comparison.

Figure 7: The streamlines in the distributor section under low inlet flow-rate condition $\left(Q_{i n}=0.18 \mathrm{~L} \cdot \mathrm{min}^{-1}\right.$, mean $\mathrm{Re}_{c h}=100$ ). (a) PIV measurement; (b) CFD simulation Figure 8: The streamlines in the distributor section under high inlet flow-rate condition $\left(Q_{i n}=1.8 \mathrm{~L} \cdot \mathrm{min}^{-1}\right.$,
mean $\left.\operatorname{Re}_{c h}=1000\right)$. (a) PIV measurement; (b) CFD simulation

Under low inlet flow-rate condition $\left(Q_{i n}=0.18 \mathrm{~L} \cdot \mathrm{min}^{-1}\right.$; mean $\left.\operatorname{Re}_{c h}=100\right)$, both the flow streamlines in the distributor section obtained by PIV and CFD methods seem smooth and 
regular. Because of the small opening of parallel channel with respect to the inlet tube, a part

2

3

4

5

6

7

8

9

10

11

12

13

14

15

16

17 of fluid flow changes the direction by $90^{\circ}$, passing horizontally towards the edge wall of the distributor. Some inlets located in the middle of the network (e.g., channels 3-11) are partially skipped by the fluid flow, indicated by the $\sigma_{k}$ values smaller than 1.0. Owing to the back-flow from the edge wall (boundary effect), the farthest channels (e.g., channels 14-15) receive relatively higher amount of fluid flow than the average $\left(\sigma_{k}>1.0\right)$. A vortex next to the inlet tube may be easily observed both on PIV and CFD images, with similar location and size. This also explains the good agreement between PIV and CFD results on flow-rate distribution among parallel channels.

Under high inlet flow-rate condition $\left(Q_{i n}=1.8 \mathrm{~L} \cdot \mathrm{min}^{-1}\right.$; mean $\left.\mathrm{Re}_{c h}=1000\right)$ however, the flow profiles in the distributor chamber become irregular, indicated by the existence of more and larger vortices and recirculation flows. The images of flow streamlines obtained by PIV and CFD methods appear to be globally similar but slight different in detail, especially on the size of vortices in $y$ direction. This implies that the locations and sizes of vortices in the distributor section are the key factors influencing the flow distribution properties among parallel channels.

\section{Conclusions and perspectives}

In this work, the fluid flow distribution properties in a parallel mini-channels fluidic network have been measured using PIV technique. The standard 2D-2C PIV has been employed to measure the mass flow-rates by dividing the cross-sections of channels into a number of sampling planes. The flow-rates obtained by PIV technique have been compared with the values of flowmeter for a double-channels device and with CFD simulation results for a 15channels fluidic network. Based on the analyses presented above, the following conclusions may be reached:

- PIV technique provides the advantages of whole field and non-intrusive measurement. It is a relatively accurate and reliable experimental method for flow-rate measurement, with the maximum possible uncertainty of $13.1 \%$ under our tested conditions. The measurement procedure used in this study may serve in the following relevant researches.

- Non-uniform flow distributions among multiple parallel channels are observed by both PIV and CFD methods. Under low flow-rate condition $\left(Q_{i n}=0.18 \mathrm{~L} \cdot \mathrm{min}^{-1}\right.$; mean $\left.\mathrm{Re}_{c h}=100\right)$, CFD results show excellent agreement with the PIV measurements. Under high flow-rate condition $\left(Q_{i n}=1.8 \mathrm{~L} \cdot \mathrm{min}^{-1}\right.$; mean $\left.\mathrm{Re}_{c h}=1000\right)$, the numerical and experimental results are in good agreement for the general tendency, but noticeable discrepancies on the flow-rate in certain channels may also be observed.

- A close investigation on the flow streamlines in the distributor section indicates that the measurement discrepancies under high flow-rate condition are mainly due to the difficulties in simulation caused by turbulence and vortex flows. Actually the locations and sizes of vortices in the distributor may have a significant influence on the flow distribution. This also implies that CFD results must be validated by experimental measurements, especially under turbulent flow condition.

Once the reliable technique has been established for the precise measurement of flow distribution, the next task is how to control the flow distribution properties so as to improve the global performances of tubular process equipment or energy conversion systems. In some 


\section{Nomenclature}

$\begin{array}{cl}A & \text { perimeter } \\ d_{h} & \text { hydraulic diameter } \\ e & \text { channel depth } \\ G & \text { magnification ratio } \\ l & \text { width of the channel } \\ m & \text { mass flow-rate } \\ \bar{m} & \text { average mass flow-rate } \\ M & \text { number of channels } \\ N & \text { pixel numbers } \\ Q & \text { volume flow-rate } \\ R e & \text { Reynolds number } \\ S & \text { area of cross-section of channel } \\ \Delta t & \text { time interval between two frames } \\ U & \text { actual velocity } \\ \bar{U} & \text { mean velocity } \\ U^{\prime} & \text { measured velocity by PIV }\end{array}$

\section{Greek symbols}

$\begin{array}{cl}\varepsilon & \text { deviation of PIV } \\ \mu & \text { dynamics viscosity } \\ \rho & \text { density } \\ \sigma & \text { flow-rate ratio } \\ \text { chbscripts } & \\ \text { ch } & \text { channel } \\ f & \text { flowmeter } \\ \text { in } & \text { inlet/distributor } \\ k & \text { channel index } \\ p & \text { PIV }\end{array}$

\section{Abbreviation}

CCD Charge Coupled Device

CFD Computational Fluid Dynamics 
DUV Doppler Ultrasonic Velocimetry

FFTs Fast Fourier Transforms

HWA Hot Wire Anemometry

LDV Laser-Doppler Velocimetry

PMMA Polymethyl Methacrylate

PSP Polyamid Seeding Particles

RTD Residence Time Distribution

1

\section{References}

3

5

[1] Luo L. Heat and Mass Transfer Intensification and Shape Optimization: A Multi-scale Approach. Springer, London, 2013.

[2] Turek V, Hájek J, Jegla Z, Stéhlík P. Optimum design of fluid distribution systems in heat exchangers. Asia Pac. J. Chem. Eng. 2011; 6: 750-759.

[3] Lalot S, Florent P, Lang S, Bergles A. Flow maldistribution in heat exchangers. Appl. Therm. Eng. 1999; 19(8): 847-863.

[4] Darekar M, Singh KK, Shenoy KT, Kundu G, Rao H, Ghosh SK. Numerical simulations to evaluate basic geometrical shapes as headers for equal liquid flow distribution. Asia Pac. J. Chem. Eng. 2014; 9: 707-717.

[5] Wada Y, Schmidt MA, Jensen KF. Flow distribution and ozonolysis in gas-liquid multichannel microreactors. Ind. Eng. Chem. Res. 2006; 45(24): 8036-8042.

[6] Luo L, Fan Y, Tondeur D. Heat exchanger: From micro- to multi-scale design optimization. Int. J. Energy Res. 2007; 31: 1266-1274.

[7] Fan Y, Boichot R, Goldin T, Luo L. Flow distribution property of the constructal distributor and heat transfer intensification in a mini heat exchanger. AIChE J. 2008; 54(11): 2796-2808.

[8] Zhang Z, Li Y. CFD simulation on inlet configuration of plate-fin heat exchanger. Cryogenics 2003; 43: 673-678.

[9] Sheik Ismail L, Ranganayakulu C, Shah RK. Numerical study of flow patterns of compact plate-fin heat exchangers and generation of design data for offset and wavy fins. Int. J., Heat Mass Transfer 2009; 52(17): 3972-3983.

[10] Wang L, Fan Y, Luo L. Heuristic optimality criterion algorithm for shape design of fluid flow. $J$. Comput. Phys. 2010; 229(20): 8031-8044.

[11] Fan Z, Zhou X, Luo L, Yuan W. Experimental investigation of the flow distribution of a 2-dimensional constructal distributor. Exp. Therm. Fluid Sci. 2008; 33(1): 77-83.

[12] Kandlikar SG, Lu Z, Domigan WE, White AD, Benedict MW. Measurement of flow maldistribution in parallel channels and its application to ex-situ and in-situ experiments in PEMFC water management studies. Int. J. Heat Mass Transfer 2009; 52: 1741-1752.

[13] Kumaran MR, Kumaraguruparan G, Sornakumar T. Experimental and Numerical Studies of Header Design and Inlet/Outlet Configurations on Flow Mal-distribution in Parallel Micro-channels. Appl. Therm. Eng. 2013; 58(1-2): 205-216.

[14] Baker RC. Flow measurement handbook: industrial designs, operation principles, performance, and application. Cambridge University Press, New York, 2000.

[15] LaNasa PJ, Upp EL. Fluid flow measurement: A practical guide to accurate flow measurement (3rd edn). Butterworth-Heinemann, 2014.

[16] Kuo JTW, Yu L, Meng E. Micromachined thermal flow sensors-A review. Micromachines 2012; 3: 550573.

[17] Commenge J-M, Falk L, Corriou J-P, Matlosz M. Analysis of microstructured reactor characteristics for process miniaturization and intensification. Chem. Eng. Technol. 2005; 28(4): 446-458. 
[18] Aubin J, Prat L, Xuereb C, Gourdon C. Effect of microchannel aspect ratio on residence time distributions and the axial dispersion coefficient. Chem. Eng. Process. Process Intensif. 2009; 48(1): 554-559.

[19] Tourvieille J-N, Philippe R, de Bellefon C. Milli-channel with metal foams under an applied gas-liquid periodic flow: Flow patterns, residence time distribution and pulsing properties. Chem. Eng. Sci. 2015; 126: $406-426$.

[20] Scarano F, Reithmuller ML. Iterative multigrid approach in PIV image processing with discrete windows offset. Exp. Fluids 1999; 26: 513-523.

[21] Foucaut JM, Carlier J, Stanislas M. PIV optimization for the study of turbulent flow using spectral analysis. Meas. Sci. Technol. 2004; 8: 1427-1440.

[22] Sinton D. Microscale flow visualization. Microfluid. Nanofluid. 2004; 1: 2-21.

[23] Wereley ST, Meinhart CD. Recent advances in Micro-Particle Image Velocimetry. Annu. Rev. Fluid Mech. 2010; 42: 557-576.

[24] Lindken R, Rossi M, Grobe S, Westerweel J. Micro-Particle Image Velocimetry ( $\mu$ PIV): Recent developments, applications, and guidelines. Lab Chip 2009; 9: 2551-2567.

[25] Cierpka C, Kähler CJ. Particle image techniques for volumetric three-component (3D3C) velocity measurements in microfluidics. J. Vis. 2012; 15: 1-31.

[26] Santiago JG, Wereley ST, Meinhart CD, Beebe DJ, Adrian RJ. A particle image velocity system for microfluidics. Exp. Fluids 1998; 25: 316-319.

[27] Meinhart CD, Wereley ST, Santiago JG. PIV measurements of a microchannel flow. Exp. Fluids 1999; 27: 414-419.

[28] Hsieh S-S, Lin C-Y, Huang C-F. Liquid flow in a micro-channel. J. Micromech. Microeng. 2004; 14: 436-445.

[29] Kitagawa A, Hishida K, Kodama Y. Flow structure of microbubble-laden turbulent channel flow measured by PIV combined with the shadow image technique. Exp. Fluids 2005; 38: 466-475.

[30] Yoon SY, Ross JW, Mench MM, Sharp KV. Gas-phase particle image velocimetry (PIV) for application to the design of fuel cell reactant flow channels. J. Power Sources 2006; 160: 1017-1025.

[31] Hoffmann M, Schlüter M, Räbiger N. Experimental investigation of liquid-liquid mixing in T-shaped micro-mixers using $\mu$-LIF and $\mu$-PIV. Chem. Eng. Sci. 2006; 61: 2968-2976.

[32] Lima R, Wada S, Tsubota K, Yamaguchi T. Confocal micro-PIV measurements of three-dimensional profiles of cell suspension flow in a square microchannel. Meas. Sci. Technol. 2006; 17: 797-808.

[33] Silva G, Leal N, Semiao V. Micro-PIV and CFD characterization of flows in a microchannels: Velocity profiles, surface roughness and Poiseuille numbers. Int. J., Heat Fluid Flow 2008; 29: 1211-1220.

[34] Shinohara K, Sugii Y, Aota A, Hibara A, Tokeshi M, Kitamori T, Okamoto K. High-speed micro-PIV measurements of transient flow in microfluidic devices. Meas. Sci. Technol. 2004; 15: 1965-1970.

[35] Wen J, Li Y, Zhou A, Zhang K. An experimental and numerical investigation of flow patterns in the entrance of plate-fin heat exchanger. Int. J. Heat Mass Transfer 2006; 49: 1667-1678.

[36] Westerweel J. Fundamentals of digital particle image velocimetry. Meas. Sci. Technol. 1997; 8: 13791392.

[37] Hinze JO. Turbulence. McGraw Hill Company, 1959.

[38] Tondeur D, Fan Y, Commenge J-M, Luo L. Uniform flows in rectangular lattice networks. Chem. Eng. Sci. 2011; 66(21): 5301-5312.

[39] Pistoresi C, Fan Y, Luo L. Numerical study on the improvement of flow distribution uniformity among parallel mini-channels. Chem. Eng. Process. Process Intensif. 2015; 95: 63-71. 
[40] Milman OO, Spalding DB, Fedorov VA. Steam condensation in parallel channels with nonuniform heat removal in different zones of heat-exchange surface. Int. J. Heat Mass Transfer 2012; 55: 6054-6059.

[41] Boerema N, Morrison G, Taylor R, Rosengarten G. High temperature solar thermal central-receiver billboard design. Sol. Energy 2013; 97: 356-368.

[42] Wei M, Fan Y, Luo L, Flamant G. Fluid flow distribution optimization for minimizing the peak temperature of a tubular solar receiver. Energy 2015; 91: 663-677.

[43] Luo L, Wei M, Fan Y, Flamant G. Heuristic shape optimization of baffled fluid distributor for uniform flow distribution. Chem. Eng. Sci. 2015; 123: 542-556.

[44] Wei M, Fan Y, Luo L, Flamant G. CFD-based evolutionary algorithm for the realization of target fluid flow distribution among parallel channels. Chem. Eng. Res. Des. 2015; 100: 341-352.

\section{List of Figures}

Figure 1: Schematic diagram of experimental setup

Figure 2: Schematic view of the experimental workbench for subtle movements of the test-section

Figure 3: The geometry and dimensions of double-channels device: (a) schematic view (unit: mm); (b) photo view

Figure 4: Example of fluid flow velocity profile at the cross-sectional surface of a channel

Figure 5: The geometry and dimensions of 15-channels fluidic network. (a) Cube A; (b) Cube B (unit: mm); (c) Photo view after assembling

Figure 6: The flow distribution properties obtained by PIV and CFD under different inlet flow-rate conditions. (a) $Q_{i n}=0.18 \mathrm{~L} \cdot \mathrm{min}^{-1}$, mean $\operatorname{Re}_{c h}=100$; (b) $Q_{i n}=1.8 \mathrm{~L} \cdot \mathrm{min}^{-1}$, mean $\operatorname{Re}_{c h}=1000$

Figure 7: The streamlines in the distributor section under low inlet flow-rate condition $\left(Q_{i n}=0.18 \mathrm{~L} \cdot \mathrm{min}^{-1}\right.$, mean $\mathrm{Re}_{c h}=100$ ). (a) PIV measurement; (b) CFD simulation

Figure 8: The streamlines in the distributor section under high inlet flow-rate condition $\left(Q_{i n}=1.8 \mathrm{~L} \cdot \mathrm{min}^{-1}\right.$, mean $\mathrm{Re}_{c h}=1000$ ). (a) PIV measurement; (b) CFD simulation

\section{List of Tables}

Table 1: Comparison between various frequently-used microfluidic measurements

Table 2: The results of different cases in pre-test 
1

2

3

4

5

6

7

8

9

10

11

12

13

14

15

16

17

18

19

20

21

22

23

24

25

26

27

28

29

30

31

32

33

34

35

36

37

38

39

40

41

42

43

44

45

46

47

48

49

50

51

52

53

54

55

56

57

58

59

60

1

Table 1: Comparison between various frequently-used microfluidic measurements

\begin{tabular}{|c|c|c|c|c|}
\hline Name & $\begin{array}{c}\text { Intrusive/ } \\
\text { non- } \\
\text { intrusive }\end{array}$ & Spatial resolution & $\begin{array}{l}\text { Tracer } \\
\text { needed }\end{array}$ & Required instruments \\
\hline $\begin{array}{l}\text { Weighting } \\
\text { method }\end{array}$ & Yes & $\begin{array}{l}\text { No flow field information; flow-rate } \\
\text { measurement only }\end{array}$ & No & Container; digital balance; stop watch \\
\hline RTD & No & $\begin{array}{l}\text { No flow field information; flow-rate } \\
\text { measurement only }\end{array}$ & Yes & $\begin{array}{c}\text { Tracer injector; fast camera; concentration meter } \\
\text { or spectrometer }\end{array}$ \\
\hline HWA & Yes & $\begin{array}{l}\text { Single point measurement; local } \\
\text { scalar flow velocity }\end{array}$ & No & $\begin{array}{c}\text { Hot-wire probe; analog-to-digital convertor; data } \\
\text { processing }\end{array}$ \\
\hline LDV/DUV & No & $\begin{array}{l}\text { Single point measurement; local } \\
\text { vectorial flow velocity }\end{array}$ & Yes & $\begin{array}{l}\text { Continuous laser (or Ultrasonic); beam-splitter; } \\
\text { light collector; data processing }\end{array}$ \\
\hline PIV & No & $\begin{array}{l}\text { Whole flow field measurement; } \\
\text { velocity profiles }\end{array}$ & Yes & $\begin{array}{c}\text { Double pulsed laser; CCD camera; lens; data } \\
\text { processing }\end{array}$ \\
\hline
\end{tabular}

2 
1

Table 2: The results of different cases in pre-test

$\begin{array}{ll}2 & 1 \\ 3 & 1\end{array}$

\begin{tabular}{|c|c|c|c|c|c|}
\hline No. Case & $\begin{array}{l}\text { Number of frames } \\
\text { for each plane }\end{array}$ & $\underset{\left(\mathbf{L} \cdot \min ^{-1}\right)}{Q_{f}}$ & $\underset{\left(\mathbf{L} \cdot \min ^{-1}\right)}{Q_{p}}$ & $\varepsilon_{\min }$ & $\varepsilon_{\max }$ \\
\hline \multirow{2}{*}{ Case $1(\mathrm{CH} 1)$} & 200 & 1.470 & 1.4081 & $6.67 \%$ & $13.1 \%$ \\
\hline & 375 & 1.470 & 1.4096 & $6.79 \%$ & $13.0 \%$ \\
\hline \multirow{2}{*}{ Case $2(\mathrm{CH} 2)$} & 200 & 1.450 & 1.4170 & $9.00 \%$ & $11.4 \%$ \\
\hline & 375 & 1.450 & 1.4174 & $9.03 \%$ & $11.4 \%$ \\
\hline Case $3(\mathrm{CH} 1+\mathrm{CH} 2)$ & 200 & 3.085 & $1.5275(\mathrm{CH} 1)+1.4714(\mathrm{CH} 2)=2.9989$ & $2.18 \%$ & $7.30 \%$ \\
\hline
\end{tabular}

2 


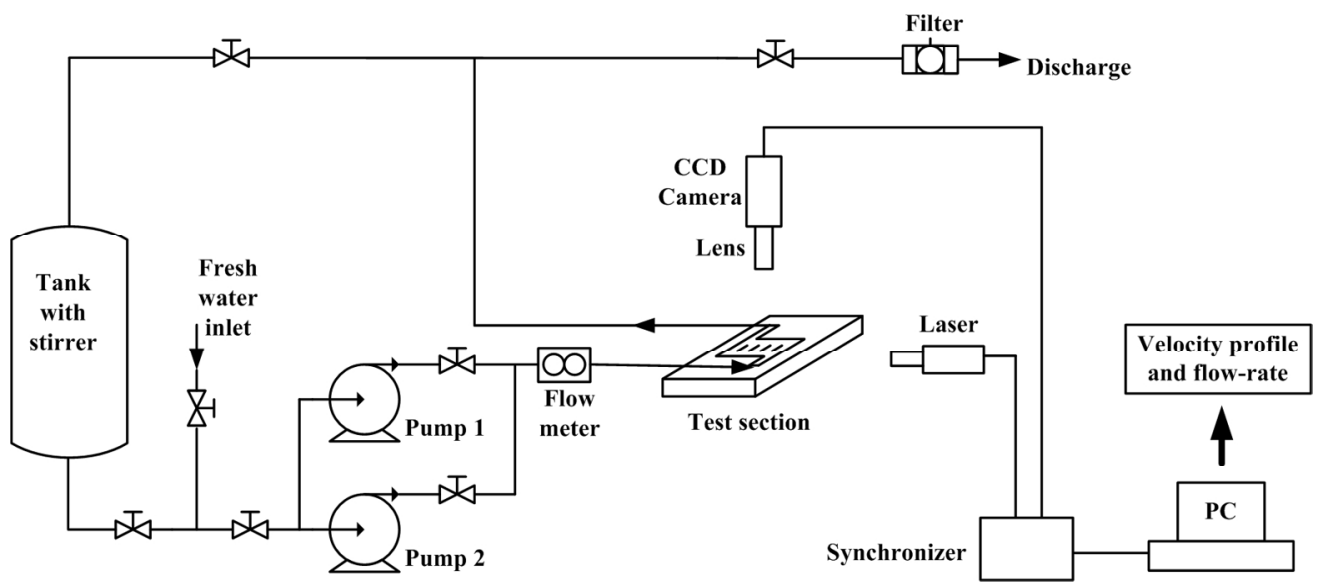

$150 \times 66 \mathrm{~mm}(300 \times 300 \mathrm{DPI})$ 


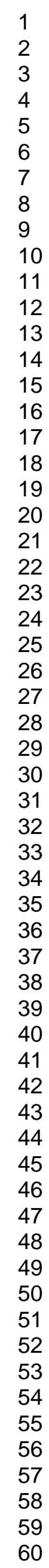

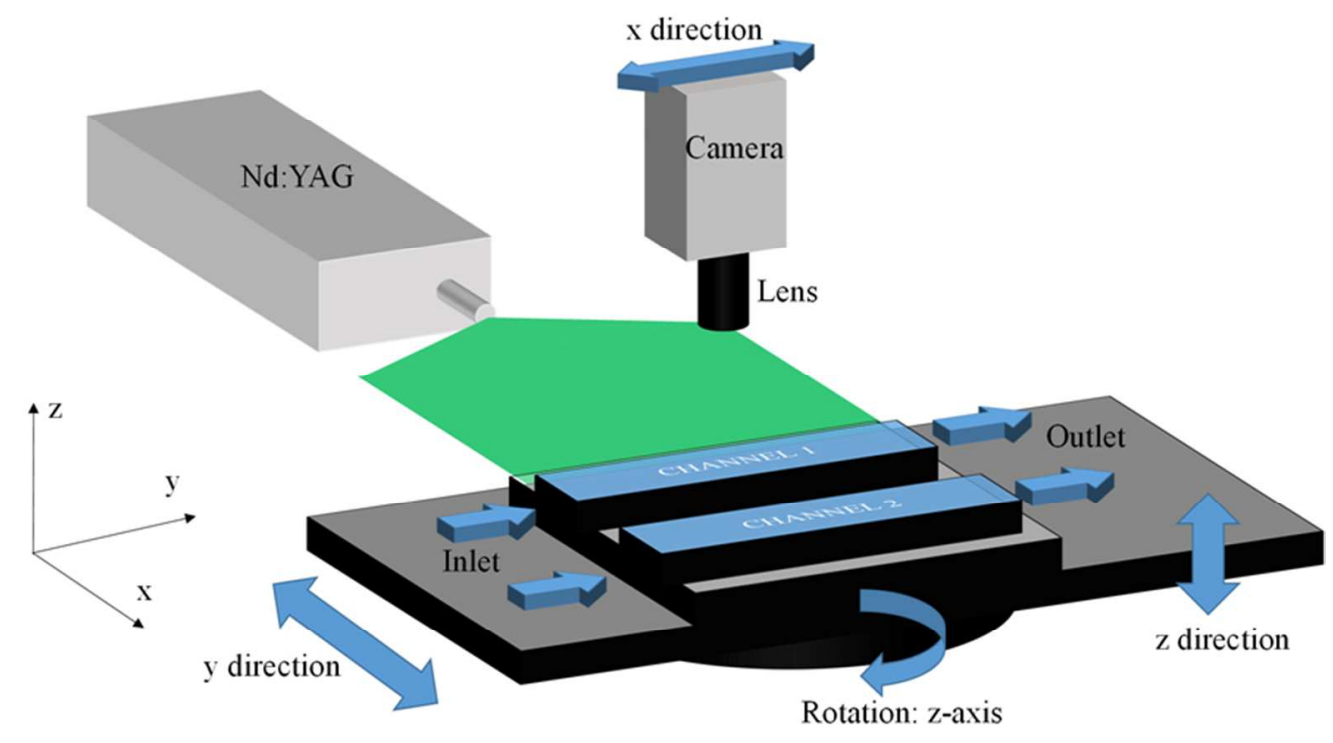

$75 \times 44 \mathrm{~mm}(300 \times 300$ DPI $)$ 


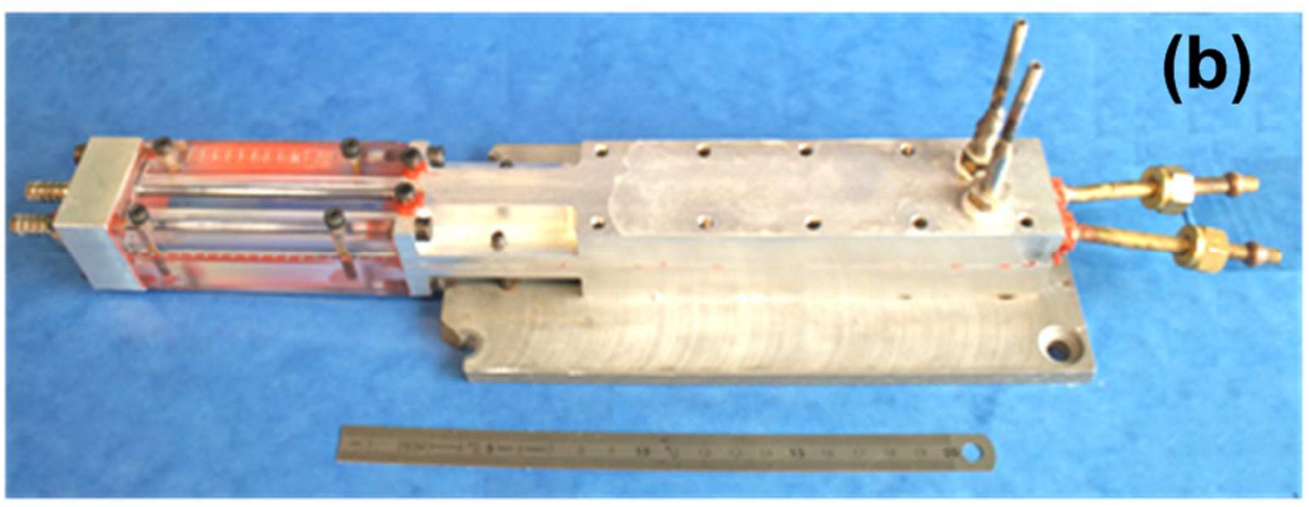

$75 \times 65 \mathrm{~mm}(300 \times 300$ DPI $)$ 


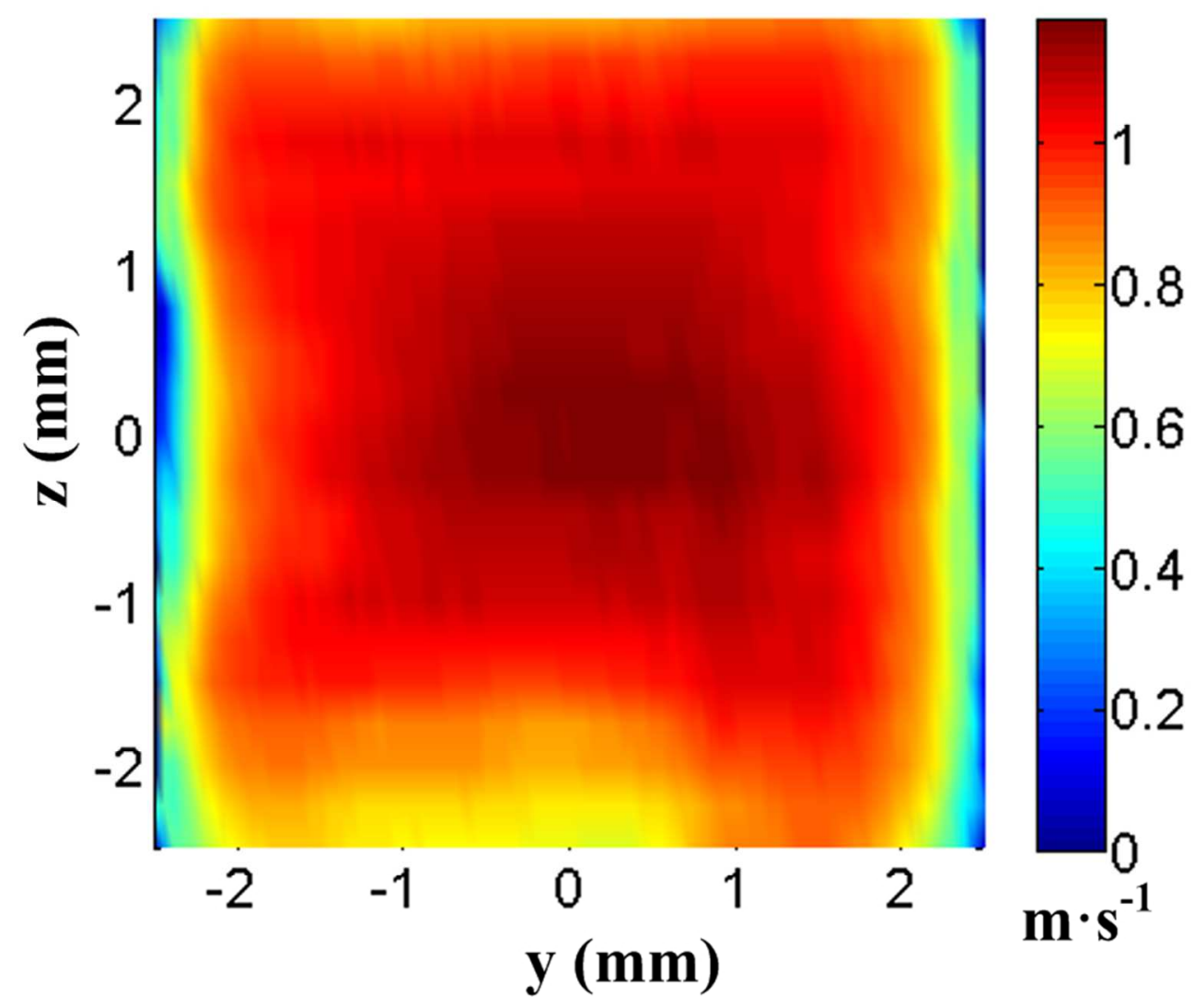

$75 \times 62 \mathrm{~mm}(300 \times 300 \mathrm{DPI})$ 


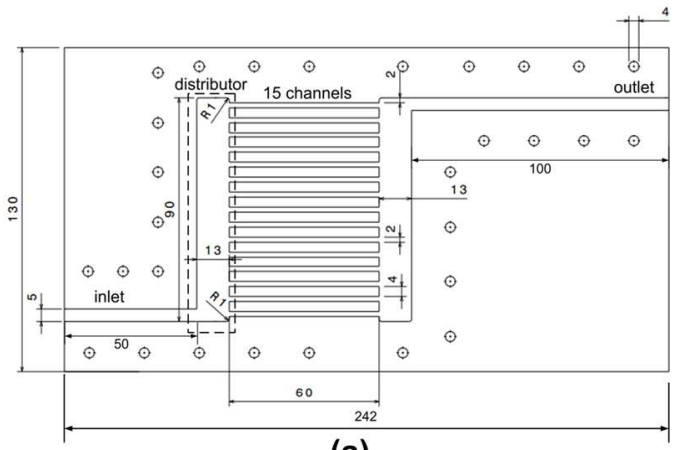

(a)

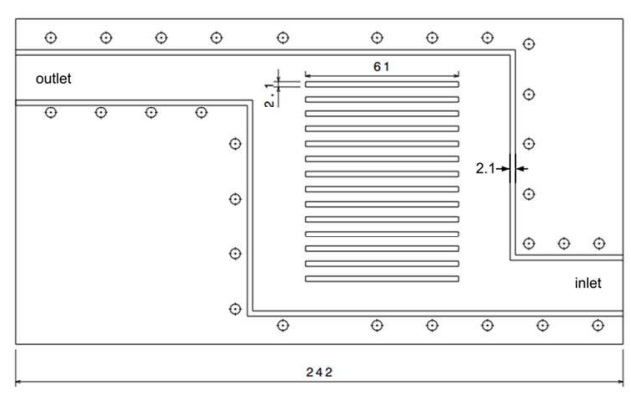

(b)

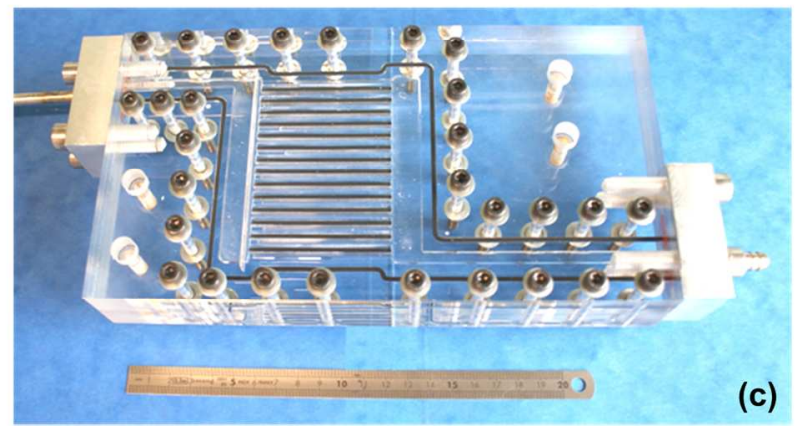

$150 \times 103 \mathrm{~mm}(300 \times 300$ DPI $)$ 


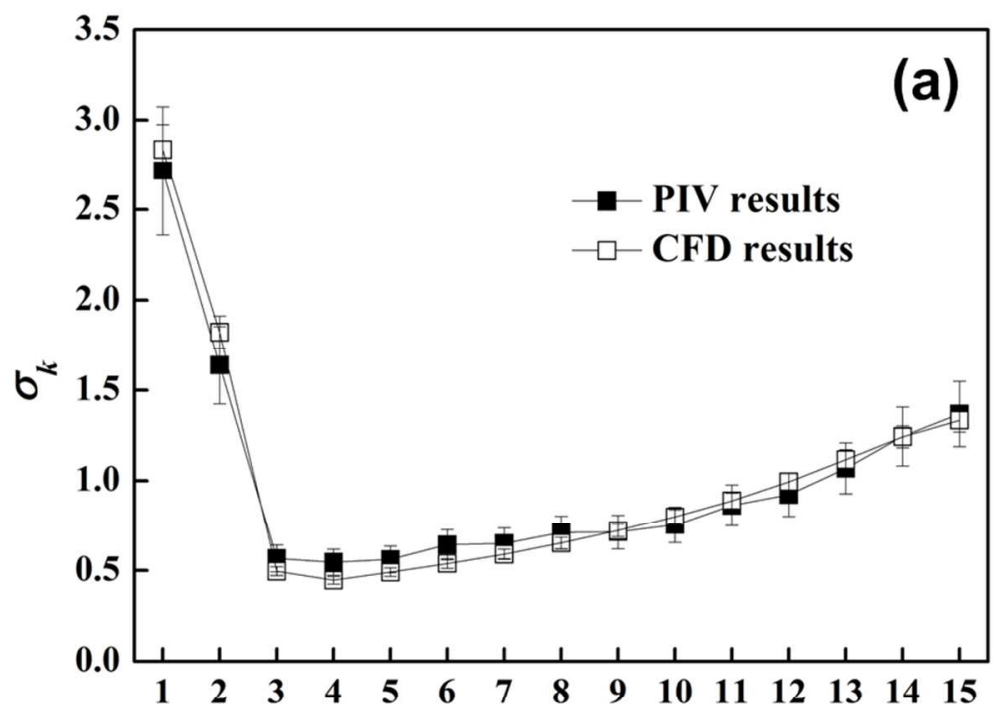

Serial number of channels

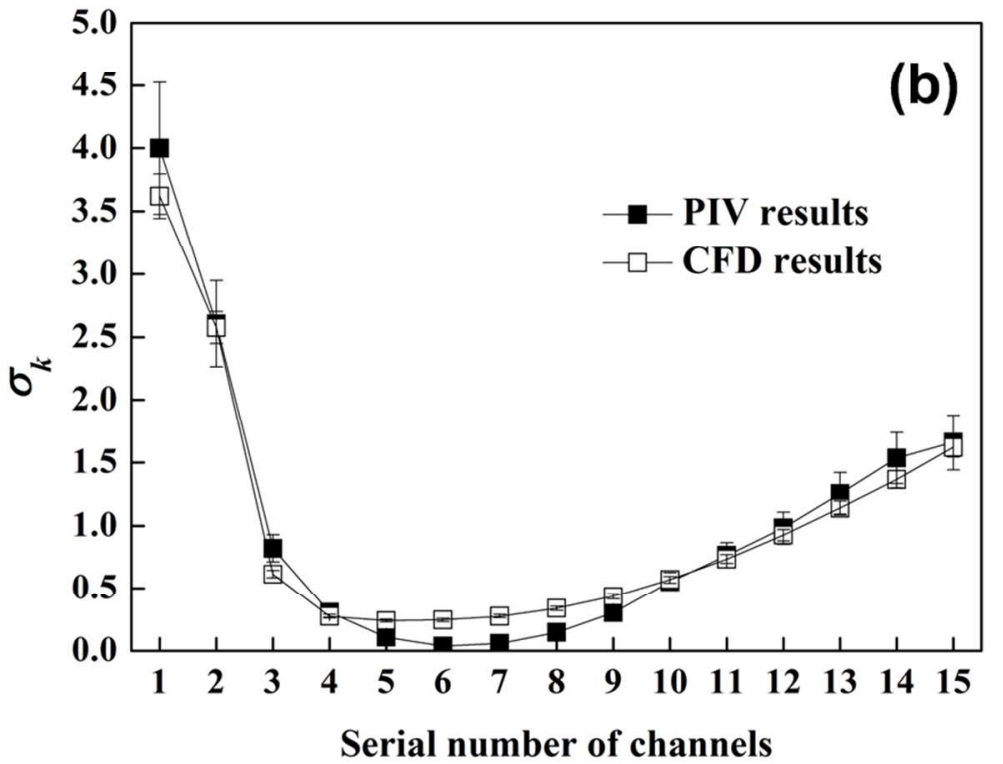

$75 \times 115 \mathrm{~mm}(300 \times 300$ DPI $)$ 


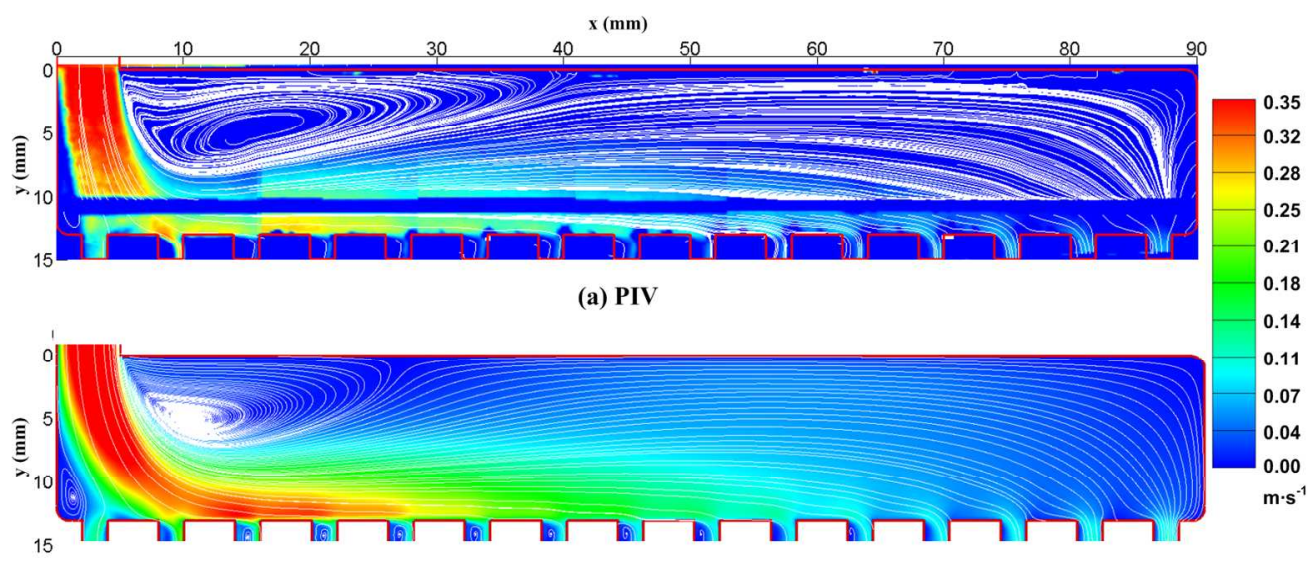

(b) CFD

$150 \times 67 \mathrm{~mm}(300 \times 300$ DPI $)$ 


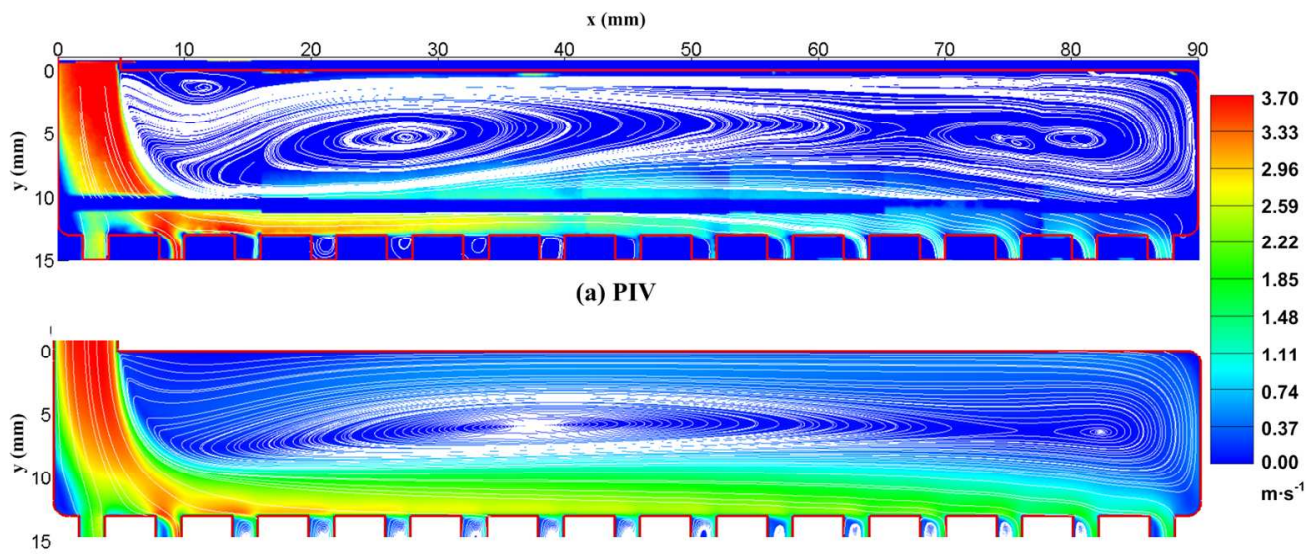

(b) CFD

$150 \times 67 \mathrm{~mm}(300 \times 300$ DPI $)$ 